This article was downloaded by:[Statsbiblioteket Tidsskriftafdeling]

On: 18 February 2008

Access Details: [subscription number 769848914]

Publisher: Routledge

Informa Ltd Registered in England and Wales Registered Number: 1072954

Registered office: Mortimer House, 37-41 Mortimer Street, London W1T 3JH, UK

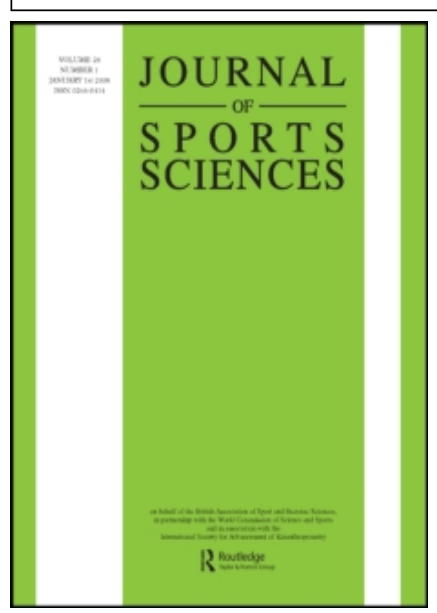

\title{
Journal of Sports Sciences
}

Publication details, including instructions for authors and subscription information:

http://www.informaworld.com/smpp/title content=t713721847

Biomechanical differences in soccer kicking with the

preferred and the non-preferred leg

H. C. Dörge; T. Bull Andersen; H. Sørensen; E. B. Simonsen

Online Publication Date: 01 April 2002

To cite this Article: Dörge, H. C., Andersen, T. Bull, Sørensen, H. and Simonsen, E. B. (2002) 'Biomechanical differences in soccer kicking with the preferred and the non-preferred leg', Journal of Sports Sciences, 20:4, 293 - 299

To link to this article: DOI: $10.1080 / 026404102753576062$

URL: http://dx.doi.org/10.1080/026404102753576062

\section{PLEASE SCROLL DOWN FOR ARTICLE}

Full terms and conditions of use: http://www.informaworld.com/terms-and-conditions-of-access.pdf

This article maybe used for research, teaching and private study purposes. Any substantial or systematic reproduction, re-distribution, re-selling, loan or sub-licensing, systematic supply or distribution in any form to anyone is expressly forbidden.

The publisher does not give any warranty express or implied or make any representation that the contents will be complete or accurate or up to date. The accuracy of any instructions, formulae and drug doses should be independently verified with primary sources. The publisher shall not be liable for any loss, actions, claims, proceedings, demand or costs or damages whatsoever or howsoever caused arising directly or indirectly in connection with or arising out of the use of this material. 


\title{
Biomechanical differences in soccer kicking with the preferred and the non-preferred leg
}

\author{
H.C. DÖRGE, ${ }^{1}$ T. BULL ANDERSEN, ${ }^{2 *}$ H. SØRENSEN ${ }^{2}$ and E.B. SIMONSEN ${ }^{2}$ \\ ${ }^{1}$ Institute of Sports, University of Aarhus, Aarhus and ${ }^{2}$ Institute of Medical Anatomy, The Panum Institute, University of \\ Copenhagen, Copenhagen, Denmark
}

Accepted 11 October 2001

\begin{abstract}
The aims of this study were to examine the release speed of the ball in maximal instep kicking with the preferred and the non-preferred leg and to relate ball speed to biomechanical differences observed during the kicking action. Seven skilled soccer players performed maximal speed place kicks with the preferred and the nonpreferred leg; their movements were filmed at $400 \mathrm{~Hz}$. The inter-segmental kinematics and kinetics were derived. A coefficient of restitution between the foot and the ball was calculated and rate of force development in the hip flexors and the knee extensors was measured using a Kin-Com dynamometer.

Higher ball speeds were achieved with the preferred leg as a result of the higher foot speed and coefficient of restitution at the time of impact compared with the non-preferred leg. These higher foot speeds were caused by a greater amount of work on the shank originating from the angular velocity of the thigh. No differences were found in muscle moments or rate of force development. We conclude that the difference in maximal ball speed between the preferred and the non-preferred leg is caused by a better inter-segmental motion pattern and a transfer of velocity from the foot to the ball when kicking with the preferred leg.
\end{abstract}

Keywords: dynamics, kicking, soccer.

\section{Introduction}

It is important to achieve a high ball speed in soccer kicking, since this gives the goalkeeper less time to react, thus improving one's chances of scoring. The instep soccer place kick is one of the most analysed kicking actions in soccer (Zernicke and Roberts, 1976; Asami and Nolte, 1983; Putnam and Dunn, 1987; Luhtanen, 1988; Dörge et al., 1999). It has been shown that the most successful goal scorers are those players who are able to score with both feet (Starosta, 1988). Starosta (1988) concluded that the development of left-right symmetry in shooting should form part of the preparation of soccer players. Although several studies have described the dynamics of the place kick (Zernicke and Roberts, 1976; Dunn and Putnam, 1988; Luhtanen, 1988; Lees and Nolan, 1998; Dörge et al., 1999) and the biomechanical determinants that affect the speed of the ball (Plagenhoef, 1971; Isokawa and Lees, 1988; Bull

\footnotetext{
* Address all correspondence to Thomas Bull Andersen, Department of Sport Science, University of Aarhus, Katrinebjergvej 89C, DK-2800 Aarhus, Denmark. e-mail: tbull@idraet.au.dk
}

Andersen et al. 1999), only one study has investigated kinematic differences when kicking for maximum ball speed with the preferred and the non-preferred leg (McLean and Tumilty, 1993).

During the kicking movement, the leg functions as an open kinetic chain. The motion pattern of kicking is generally accepted as a proximal-to-distal sequence of segmental motions in which the proximal segment (the thigh) initiates the movement, causing the more distal segment (shank and foot) to lag behind, followed by a deceleration of the proximal segment and an acceleration of the more distal segment just before impact (Lees, 1996; Lees and Nolan, 1998). During the kicking movement, the segments of the kicking leg move by rotating about an imaginary axis of rotation that passes through the proximal joint of the segment. The motion of rotating body segments in kicking can be described in terms of angular position, velocity and acceleration. The linear velocity of the centre of mass of the rotating foot $\left(v_{\text {foot }}\right)$ hitting the ball is directly proportional to the product of the angular velocity and the radius of rotation of the consecutive body segments and the linear velocity of the hip joint. The timing of these 
rotational movements is important for the impact of the foot with the ball. Putnam (1983) used the time between peak angular velocity of the thigh until the beginning of knee extension as a measure of timing during kicking with the preferred leg. Luhtanen (1988) used the interval between the shank reaching maximum angular velocity and impact as a measure of timing. To our knowledge, no study has dealt with kinetic differences between kicking with the preferred and the non-preferred leg.

The angular acceleration of the link segment system of the kicking leg depends on energy transfer between segments, the muscle moments producing the rotation of the thigh, shank and foot and the rotational inertia of these leg segments. The mechanics of the collision between the foot and the ball can be considered using the following equation, where the speed of the ball after impact is expressed as (Bull Andersen et al., 1999):

$$
v_{\text {ball }}=\frac{v_{\text {foot }} \cdot I_{\text {shank }} \cdot(1+e)}{I_{\text {shank }}+m_{\text {ball }} \cdot r^{2}}
$$

where $v_{\text {ball }}$ is the speed of the ball after impact, $v_{\text {foot }}$ is the speed of the centre of mass of the foot before impact, $I_{\text {shank }}$ is the moment of inertia of the shank-foot segment, $m_{\text {ball }}$ is the mass of the ball, $r$ is the distance from the knee joint to the centre of the impact and $e$ is the coefficient of restitution. The coefficient of restitution, $e$, is an indicator of transfer of momentum from the foot to the ball. This transfer depends on which part of the foot hits the ball, where the ball is hit and the stiffness of the foot during the impact (Lees, 1996). Equation (1) implies that ball speed is dependent on the speed of the foot, the moment of inertia of the shank segment and the coefficient of restitution.

The aims of the present study were to examine the release speed of the ball in maximal instep kicking with the preferred and the non-preferred leg and to relate ball speed to biomechanical differences observed during kicking. We also compared the rate of force development of the knee extensors and of the hip flexors between the preferred and the non-preferred leg.

\section{Material and methods}

\section{Participants}

In a pre-test, 30 skilled players kicked a ball eight times with each leg and ball speed was measured using a Doppler radar gun. Of these players, the seven with the most constant ball speed, for both the preferred and the non-preferred leg, were chosen to participate in the study (Table 1 ). The preferred leg of each participant
Table 1. The mass, height and ball speeds of the seven participants in the present study

\begin{tabular}{lll}
\hline & Mean $\pm s$ & Range \\
\hline Mass (kg) & $74.4 \pm 10.9$ & $66.0-96.0$ \\
Height $(\mathrm{m})$ & $1.81 \pm 0.06$ & $1.71-1.88$ \\
Ball speed $\left(\mathrm{m} \cdot \mathrm{s}^{-1}\right)$ & & \\
$\quad$ preferred leg & $24.7 \pm 2.5^{*}$ & $20.3-28.4$ \\
non-preferred leg & $21.5 \pm 2.0^{*}$ & $19.0-24.5$ \\
\hline
\end{tabular}

* Significant difference between the preferred and non-preferred legs $(P<0.05)$.

was identified by the ball speed during the pre-test. All participants provided informed consent after the local ethics committee had approved the study.

\section{The soccer place kick}

The participants performed maximal velocity instep place kicks of a stationary ball; essentially, this corresponds to the penalty kick in soccer. A ball of standard size and standard inflation (Fédération Internationale de Football Association, FIFA, standard) was kicked $4 \mathrm{~m}$ towards a target $1 \times 1 \mathrm{~m}$ in size. As it was easy to hit the target, the participants were asked to hit the ball as hard as possible. To minimize movement in the frontal plane, the participants were restricted to a $3 \mathrm{~m}$ straight run-up from a position directly behind the ball, which made the kick suitable for two-dimensional analysis. An approach angle of $30-45^{\circ}$ usually improves the resultant ball speed (Isokawa and Lees, 1988), but such an approach introduces errors in a two-dimensional analysis.

Each participant (Table 1) performed three instep kicks with both the preferred and the non-preferred leg. The trial that produced the highest linear ball speed just after impact for both the preferred and the nonpreferred leg was selected for further analysis. The order of testing was randomized between the preferred and the non-preferred leg.

\section{Cinematography}

A $16 \mathrm{~mm}$ high-speed cine camera (Teledyne DBM 45), operating at a frame rate of $400 \mathrm{~Hz}$, was placed $10 \mathrm{~m}$ from and perpendicular to the sagittal plane of motion. A square wave pulse generated by the camera indicated the exposure of each single frame. This signal was sampled by a DT-2801-A analog-to-digital converter (Data Translation, Inc., Marlboro, MA) operating at $1000 \mathrm{~Hz}$ and fed to an IBM PC DX2 clone; the signal was subsequently examined to verify the accuracy of the filming rate. Reflective markers were placed laterally on 
the kicking leg over bony protuberances corresponding to the estimated axis of rotation on the following joints: the hip joint, the knee joint, the ankle joint and the fifth metatarsophalangeal joint. The anatomical landmarks used to detect the axes were the major trochanter, the lateral epicondyle of the femur, the lateral malleolus and lateral aspect of the distal head of the fifth metatarsus. In addition, a marker was placed on the highest point of the iliac crest.

The $16 \mathrm{~mm}$ films were transferred to video using a film projector with a built-in video camera (Elmo TRV$16 \mathrm{G} / \mathrm{CCD})$. The coordinates of the markers were digitized using the video-based Ariel Performance Analysis System (APAS).

Displacement data from the instant at which the kicking leg was lifted from the ground until impact were filtered using a digital fourth-order Butterworth lowpass filter with $0^{\circ}$ phase lag (Winter, 1990). The ends of the signal were extrapolated by reflection in both the $\mathrm{x}$ - and $\mathrm{y}$-directions, so that the slopes of the original and extrapolated sequence were matched at the endpoint. After filtering, the extrapolated sequences were removed. Optimal cut-off frequencies $(6-10 \mathrm{~Hz})$ were determined by residual analysis (Winter, 1990). From the filtered displacement data, angular velocities and accelerations, and linear velocities and accelerations, of the hip, knee, ankle and metatarsophalangeal joints and the ball were derived by finite difference computation.

An inverse dynamics method starting at the open end, the ankle, was used to calculate the muscle moment about the hip and knee joints (Winter, 1990) and to calculate the motion-dependent joint reaction forces acting as moments on the shank. Putnam (1991) described the moments acting on the shank using the equation shown in Table 2 .

The left-hand side of equation (2) is the resultant moment on the shank-foot segment about the knee joint. This moment can be decomposed into the muscle moment, a moment originating from gravity on the shank crossed by a vector from the centre of mass to the knee joint, a moment originating from the linear acceleration of the knee due to the angular velocity of the thigh, a moment originating from the linear acceleration of the knee due to the angular acceleration of the thigh and moments from the linear acceleration of the hip joint in the horizontal and vertical directions. Masses and moments of inertia of the thigh, shank and foot were calculated following the procedure of Winter (1990).

All moments on the shank change the angular kinetic energy of the shank. This can be calculated as the product of the moment, the angular velocity and the instant at which the moment is applied. In this study, we calculated the energy from each moment from the instant at which the angular velocity of the shank was zero until impact.

\section{Coefflient of restitution}

The coefficient of restitution, $e$, was calculated using equation (1). Ball speed was determined by digitizing the first 10 frames after the ball had left the foot, with the same endpoint filtering as for the reflective markers on the body. Foot speed at impact was calculated as the speed of the mid-point between the marker on the ankle joint and the marker on the distal head of the fifth metatarsophalangeal joint - that is, the centre of mass of the foot. The moment of inertia of the shank-foot segment was calculated following the procedure of Winter (1990) and the distance between the knee joint and the centre of mass of the foot was found from the position data. The mass of the ball was $0.45 \mathrm{~kg}$ (FIFA standard).

\section{Rate of force development}

The rate of force development of the knee extensors and the hip flexors was measured using a Kin-Com dynamometer (Kinetic Communicator, Chattex Corp., Chattanooga, USA). After a warm-up, the participants sat in the dynamometer with the seat and the back of the dynamometer aligned. This angle was chosen to reflect

Table 2. Equation used to describe the moments acting on the shank (after Putnam, 1991)

\begin{tabular}{rlrl}
$I_{\text {shank }} \cdot \boldsymbol{\alpha}_{\text {shank }}$ & $=\mathbf{T}_{\text {knee }}$ & & (moment due to muscle force) \\
& $+m_{\text {shank }} \cdot \mathbf{g} \times \mathbf{r}_{\text {shank }}$ & & (gravity) \\
& $+m_{\text {shank }} \cdot \mathbf{r}_{\text {shank }} \times\left(-\omega_{\text {thigh }}^{2} \cdot \mathbf{r}_{\text {thigh }}\right)$ & & (angular thigh velocity) \\
& $+m_{\text {shank }} \cdot \mathbf{r}_{\text {shank }} \times\left(\boldsymbol{\alpha}_{\text {thigh }} \cdot \mathbf{r}_{\text {thigh }}\right)$ & & (angular thigh acceleration) \\
& $+m_{\text {shank }} \cdot \mathbf{r}_{\text {shank }} \times \mathbf{a}_{\mathrm{x} \text {, hip }}$ & & (horizontal hip acceleration) \\
& $+m_{\text {shank }} \cdot \mathbf{r}_{\text {shank }} \times \mathbf{a}_{\mathrm{y} \text {, hip }}$ & & (vertical hip acceleration) \\
\hline
\end{tabular}

Note: $I$ is the moment of inertia, $\alpha$ is angular acceleration, $\mathrm{T}$ is muscle moment of force, $m$ is mass, $\mathbf{g}$ is gravitional acceleration, $\mathbf{r}$ is the distance between the knee joint and the centre of mass, $\omega$ is the angular velocity and $\mathbf{a}$ is linear acceleration. Variables in bold face are vectors. 
the hip angle at the beginning of knee extension during the soccer kick (Lees, 1996; Dörge et al., 1999). The arm of the dynamometer was then attached to the shank $5 \mathrm{~cm}$ above the lateral malleolus at a knee angle of $90^{\circ}$. The participants were instructed to extend the knee as forcefully and as quickly as possible upon a given signal. This test was performed three times on each leg. The order of testing was randomized. After measurement of the rate of force development of the knee extensors, the hip flexors were assessed in the same way at a hip angle of $180^{\circ}$ and with the Kin-Com arm attached 5 $\mathrm{cm}$ from the lateral femoral condyle. Rate of force development was calculated after 10, 20 and $30 \mathrm{~ms}$ and as the maximal rate. These intervals were chosen because the rise in muscular moments was seen within the first $30 \mathrm{~ms}$ of the concentric contraction during the kick.

The rate of force development of the hip flexors and the knee extensors was considered to be related to the kicking action. A large rate of force development enables the muscles to change from eccentric to concentric contractions more quickly, thereby causing a larger force at the beginning of the concentric phase.

\section{Statistical analysis}

Data for the two legs were analysed using a Wilcoxon's matched-pairs signed-ranks test. Differences were considered at a $P$-value of less than 0.05. Wilcoxon's matched-pairs signed-ranks test was used because the data were not normally distributed.

\section{Results}

The participants produced a higher ball speed with their preferred leg (Table 1), which was the right leg for six of the seven participants. The linear foot speed just before impact and the coefficient of restitution were higher when kicking with the preferred leg (Table 3, Fig. 1). The foot velocity originated from the linear velocity of the knee and the angular velocity of the shank. The linear speed of the knee was close to zero at impact $\left(0.06-0.56 \mathrm{~m} \cdot \mathrm{s}^{-1}\right)$ and it was similar for the preferred and the non-preferred leg $(P>0.05)$. The angular velocity of the shank at impact was greater for the preferred than the non-preferred leg $(P=0.018)$.

The total work done on the shank from from when the angular velocity of the segment was zero until impact was also greater for the preferred leg $(P=0.018)$ (Table 4). Of the joint reaction forces calculated, only the work originating from the angular velocity of the thigh was higher for the preferred leg; all other joint reaction forces performed similarly on the shank for both legs $(P>0.05)$.
Table 3. The foot speeds and angular velocities of the shank at impact

\begin{tabular}{|c|c|c|c|}
\hline & Mean & Minimum & Maximum \\
\hline \multicolumn{4}{|l|}{ Foot speed $\left(\mathrm{m} \cdot \mathrm{s}^{-1}\right)$} \\
\hline Preferred leg & $18.6^{*}$ & 16.1 & 20.3 \\
\hline Non-preferred leg & $17.0 *$ & 15.5 & 18.6 \\
\hline \multicolumn{4}{|c|}{ Angular velocity $\left(\mathrm{rad} \cdot \mathbf{s}^{-1}\right)$} \\
\hline Preferred leg & $28.1 *$ & 23.9 & 30.5 \\
\hline Non-preferred leg & $25.9 *$ & 21.1 & 29.2 \\
\hline \multicolumn{4}{|c|}{ Coeffl cient of restitution } \\
\hline Preferred leg & $0.58 *$ & 0.46 & 0.68 \\
\hline Non-preferred leg & $0.50 *$ & 0.32 & 0.66 \\
\hline
\end{tabular}

* Significant difference between the preferred and non-preferred legs $(P<0.05)$.
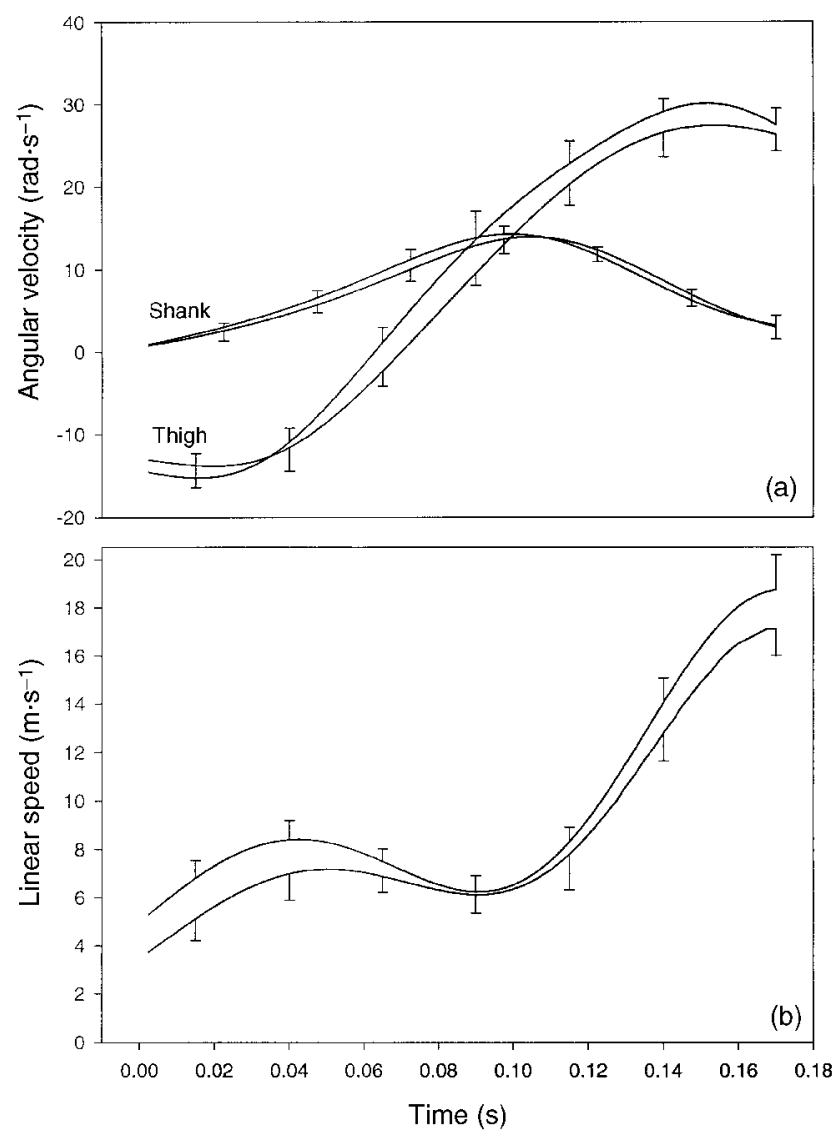

Fig. 1. (a) Angular velocities of the thigh and shank from when the angular velocity of the thigh was positive until impact. The curves are means of seven participants with the standard deviations indicated by bars pointing upwards (preferred leg) and downwards (non-preferred leg). (b) Linear speeds of the centre of mass of the foot expressed as a mean of all participants. 
Table 4. The work (J) performed on the shank, decomposed into its different sources (see text), from the time that the angular velocity of the shank segment was zero until impact (mean $\pm s$ )

\begin{tabular}{lcc}
\hline & $\begin{array}{c}\text { Preferred } \\
\text { leg }\end{array}$ & $\begin{array}{c}\text { Non-preferred } \\
\text { leg }\end{array}$ \\
\hline Muscle torque & $114 \pm 17$ & $112 \pm 22$ \\
Thigh angular velocity & $23.1 \pm 2.6^{*}$ & $20.9 \pm 3.0^{*}$ \\
Thigh angular acceleration & $-1.7 \pm 1.3$ & $-1.9 \pm 1.3$ \\
Gravitational acceleration & $8.4 \pm 0.7$ & $8.4 \pm 0.5$ \\
Horizontal acceleration of hip & $-7.1 \pm 2.4$ & $-7.4 \pm 1.8$ \\
Vertical acceleration of hip & $-13.0 \pm 3.0$ & $-13.6 \pm 3.5$ \\
Total & $123 \pm 22^{*}$ & $119 \pm 22^{*}$ \\
\hline
\end{tabular}

* Significant difference between the preferred and non-preferred legs $(P<0.05)$.

There were no differences in rate of force development between the preferred and non-preferred legs after 10,20 or $30 \mathrm{~ms}$ or in maximal force. For knee extension, the rate of force development after 10, 20 and $30 \mathrm{~ms}$ was $2470 \pm 823 \mathrm{~N} \cdot \mathrm{s}^{-1}($ mean $\pm s), 3280 \pm$ $1020 \mathrm{~N} \cdot \mathrm{s}^{-1}$ and $3890 \pm 1100 \mathrm{~N} \cdot \mathrm{s}^{-1}$ respectively for the preferred leg; for the non-preferred leg, these values were $2660 \pm 899 \mathrm{~N} \cdot \mathrm{s}^{-1}, 3840 \pm 1190 \mathrm{~N} \cdot \mathrm{s}^{-1}$ and $4590 \pm 1250 \mathrm{~N} \cdot \mathrm{s}^{-1}$ respectively. For hip flexion, the rate of force development after 10, 20 and $30 \mathrm{~ms}$ was $1950 \pm 623 \mathrm{~N} \cdot \mathrm{s}^{-1}, 2850 \pm 1050 \mathrm{~N} \cdot \mathrm{s}^{-1}$ and $4440 \pm$ $1170 \mathrm{~N} \cdot \mathrm{s}^{-1}$ respectively for the preferred leg; for the non-preferred leg, these values were $1840 \pm$ $676 \mathrm{~N} \cdot \mathrm{s}^{-1}, 2940 \pm 1250 \mathrm{~N} \cdot \mathrm{s}^{-1}$ and $4270 \pm 1620 \mathrm{~N} \cdot \mathrm{s}^{-1}$ respectively.

\section{Discussion}

The ball speed of the soccer kick depends on the speed of the foot before impact and the mechanics of the collision between the foot and the ball.

\section{Mechanicss of collision}

The coefficient of restitution assesses how the elasticity of a collision is modified by material properties of the colliding objects (Lees, 1996). In the present study, the participants wore the same type of shoe on both feet, so the differences in the coefficient of restitution must have been due to the mechanical properties of the foot and the ankle joint at impact. Photographs taken during impact show that the ankle joint and the foot joints are fully extended. A small difference in extension and stiffness of these joints would probably alter the mechanics of the collision, thereby causing the coefficients of restitution to differ.

\section{Kinematics}

Our results show that the linear speed of the foot and that of the ball was greater when kicking with the preferred than with the non-preferred leg. Even the coefficient of restitution was larger with the preferred leg.

The velocity of the foot is a function of the linear velocity of the knee and the angular velocity of the shank. Previous studies have used the angular velocity of the shank as a measure of the success of a kick (Luhtanen, 1988). However, as our results show (Fig. 1), the angular velocity of the shank was not at its maximum at the instant of impact. Therefore, we suggest that the linear velocity of the centre of mass of the foot is the best measure of the success of a kick. The linear velocity of the centre of mass of the foot is typically used in calculations of the collision between foot and ball (Lees, 1996; Bull Andersen et al., 1999).

In the present study, the linear velocity of the knee was not significantly different between legs but the angular velocity of the shank was larger when the participants kicked with their preferred leg. This meant that the larger linear velocity of the foot at the time of impact was caused by a larger angular velocity of the shank. The angular velocity of the shank was caused by moments of force acting on the segment from the time its angular velocity was zero until impact. These moments originated from the muscle forces on the segment and from the joint reaction forces. Therefore, the differences in the linear speeds of the foot between kicks with the preferred and the non-preferred leg originated from the rotatory work on the shank.

\section{Muscle forces and moments}

The product of the muscle forces caused positive net muscle moments about the hip and knee joints throughout most of the kicking motion. Positive moments of force indicate that the muscles were trying to flex the hip joint and extend the knee joint. Only just before impact have negative muscle moments been observed (Luhtanen, 1988; Lees and Nolan, 1998; Dörge et al., 1999). These muscle moments probably act as a safety mechanism and do not help to increase the angular velocity of the shank. Herring and Chapman (1992) suggested that the negative muscle moment about the hip joint should cause the angular velocity of the shank to increase (whiplash effect), but in the same period we observed a negative muscle moment about the knee joint. When the work on the shank was calculated, we observed that the negative rotational acceleration of the thigh performed negative work on the shank.

The negative muscle moment about the knee joint could also be caused by activity in the gastrocnemius 
muscle when the ankle was extended just before impact. The rotatory work on the shank from the muscle moment about the knee joint was calculated and no differences were exhibited between the preferred and the non-preferred leg. However, the total work done on the shank was larger in the preferred leg.

\section{Rate of force development}

We noted no differences in muscle moments between the two legs, which is consistent with the rates of force development recorded. A higher rate of force development could cause larger muscle moments and more work done on the segments, but we found no differences between legs.

It could be argued that muscle force parameters from an isokinetic device would be a better method, but the angular velocities during these tests would not be high enough to relate to the kicking action. During the soccer $\mathrm{kick}$, the angular velocity of the knee is up to $35 \mathrm{rad} \cdot \mathrm{s}^{-1}$, which is much higher than any isokinetic device is able to achieve.

\section{foint reaction forces and moments}

The equations developed by Putnam (1991) allowed us to calculate the different components of the moments of force from the joint reaction forces on the shank. These are usually referred to as motion-dependent joint reaction forces and originate from the angular acceleration of the thigh, the angular velocity of the thigh, gravitational acceleration of the shank and the linear acceleration of the hip joint. The only one of these motion-dependent moments to perform different work between the legs was the moment of force from the angular velocity of the thigh. The work done on the shank was greater for the preferred leg.

The angular velocity of the thigh causes an acceleration of the knee joint towards the centre of the hip joint and, when multiplied by the angle between the shank and the thigh, the joint reaction force component of the thigh angular velocity can be calculated. Our results show that the integration over time of this product was more optimal in the preferred leg. We have tried to describe this movement pattern in terms of the angular velocity of the thigh over time and the knee angle over time, but we found no significant differences between the two legs when comparing these factors.

\section{Conclusion}

The different ball speeds observed when kicking with the preferred and the non-preferred leg were caused by different foot speeds and by different collision mechanics. The difference in foot speed between the preferred and the non-preferred leg was the result of a larger angular velocity of the shank at the time of impact. This difference was caused by a greater amount of work done on the shank, because the force on the shank originated from the angular velocity of the thigh.

\section{References}

Asami, T. and Nolte, V. (1983). Analysis of powerful ball kicking. In Biomechanics VIII-B (edited by H. Matsui and K. Kobayashi), pp. 695-700. Champaign, IL: Human Kinetics.

Bull Andersen, T., Dörge, H.C. and Thomsen, F.I. (1999). Collisions in soccer kicking. Sports Engineering, 2, 121-126.

Dörge, H.C., Bull Andersen, T., Sørensen, H., Simonsen, E.B., Aagaard, H., Dyhre-Poulsen, P. and Klausen, K. (1999). EMG activity of the iliopsoas muscle and leg kinetics during the soccer place kick. Scandinavian fournal of Medicine and Science in Sports, 9, 195-200.

Dunn, E.G. and Putnam, C.A. (1988). The influence of lower leg motion on thigh deceleration in kicking. In Biomechanics $X I-B$ (edited by G. de Groot, A.P. Hollander, P.A. Huijing and G.J. Van Ingen Schenau), pp. 787-790. Amsterdam: Free University Press.

Herring, R.M. and Chapman, A.E. (1992). Effects of changes in segmental values and timing of both torque and torque reversal in simulated throws. Fournal of Biomechanics, 25, 1173-1184.

Isokawa, M. and Lees, A. (1988). A biomechanical analysis of the instep kick motion in soccer. In Science and Football (edited by T. Reilly, A. Lees, K. Davids and W.J. Murphy), pp. 449-455. London: E \& FN Spon.

Lees, A. (1996). Biomechanics applied to soccer skills. In Science and Soccer (edited by T. Reilly), pp. 123-133. London: E \& FN Spon.

Lees, A. and Nolan, L. (1998). The biomechanics of soccer: a review. Fournal of Sports Sciences, 16, 211-234.

Luhtanen, P. (1988). Kinematics and kinetics of maximal instep kicking in junior soccer players. In Science and Football (edited by T. Reilly, A. Lees, K. Davids and W.J. Murphy), pp. 449-455. London: E \& FN Spon.

McLean, B.D. and Tumilty, D. (1993). Left-right asymmetry in two types of soccer kick. British fournal of Sports Medicine, 27, 260-262.

Plagenhoef, S. (1971). The Patterns of Human Motion. Englewood Cliffs, NJ: Prentice-Hall.

Putnam, C.A. (1983). Interaction between segments during a kicking motion. In Biomechanics VIII-B (edited by H. Matsui and K. Kobayashi), pp. 688-694. Champaign, IL: Human Kinetics.

Putnam, C.A. (1991). A segment interaction analysis of proximal-to-distal sequential segment motion patterns. Medicine and Science in Sports and Exercise, 23, 130-144.

Putnam, C.A. and Dunn, E.G. (1987).Performance variations in rapid swinging motions: effects on segment interaction 
and resultant joint moments. In Biomechanics $X$ (edited by B. Jonsson), pp. 661-665. Champaign, IL: Human Kinetics. Starosta, W. (1988). Symmetry and asymmetry in shooting demonstrated by elite soccer players. In Science and Football (edited by T. Reilly, A. Lees, K. Davids and W.J. Murphy), pp. 346-355. London: E \& FN Spon.
Winter, D.A. (1990). Biomechanics and Motor Control of Human Movement. New York: Wiley.

Zernicke, R. and Roberts, E.M. (1976). Human lower extremity kinetic relationship during systematic variations in resultant limb velocity. In Biomechanics $V-B$ (edited by P.V. Komi), pp. 20-25. Baltimore, MD: University Park Press. 